\section{Malaise in psychiatric recruitment and its remedy}

Sir: I was interested to read Thompson \& Sims' article about improving recruitment to general psychiatry (Psychiatric Bulletin. April 1999, 23, 227-229). Over the last decade psychiatrists have become geographically isolated from colleagues, there is an increase in out of hours work, a proliferation of bureaucracy and many feel undervalued by the political and public perception that psychiatrists are to blame whenever their patients do anything wrong. General psychiatrists risk burn-out striving to prevent incidents, which are beyond the control of their limited resources. Model standards of care are expected at all times. In this context if recruitment to the speciality is to improve the general psychiatrist's job plan needs to be realistic.

Important factors influencing doctors' choice of career are the hours and working conditions and a self-appraisal of their own skills and aptitudes (Lambert et al, 1996). These factors are both influenced by the consultants' job plan. If general psychiatrists are expected to prevent mishaps and monitor their patients as closely in the community as they have formerly monitored them as in-patients I doubt whether many doctors will appraise themselves as being realistically able to do this unless catchment populations are reduced to realistic levels. There are still general psychiatry sectors with catchment populations more than double those recommended by the Royal College of Psychiatrists (1997). Unless this very basic issue is addressed doctors will surely continue to vote with their feet and avoid the speciality.

\section{References \\ LAMBERT, T., GOLDACRE, M., EDWARDS, C.. et al (1996) Career preferences of doctors who qualified in 1993 compared with those of doctors qualifying in 1974, 1977, 1980, and 1983. British Medical Journal, 313, 19-24. \\ ROYAL COLLEGE OF PSYCHIATRISTS (1997) Model Consultants Job Descriptions. Occasional Paper OP39, pp. 14-18. London. Royal College of Psychiatrists.}

STEVEN NAYLOR, Specialist Registrar in Old Age Psychiatry, Cornwall Healthcare Trust, St Lawrence's Hospital, Boundary Road, Bodmin, Cornwall PL31 2QT

\section{Alarming levels of stress and burn-out}

Sir: We read with interest the paper by Guthrie et al (Psychiatric Bulletin, 23, 207-213). We too have been concerned with stress and burn-out in clinical teams and recently surveyed all Child and Adolescent Mental Health teams in the north-west of England. Response rate from a postal questionnaire was $41 \%$ (males $=30 \%$, females $=70 \%$, total respondents 148 ).

We used similar outcome measures: the General Health Questionnaire (GHQ-28; Goldberg \& Williams, 1988); the Maslach Burnout Inventory, (MBI; Maslach \& Jackson, 1981); a Work Stress questionnaire (Cooper et al, 1988) and a modified version of the Job Diagnostic Survey (JDS; Hackman \& Oldham, 1975). Respondents included: consultant child psychiatrists (11.5\%), other medical staff $(6.1 \%)$, nurses $(16.2 \%)$, psychologists (13.5\%), social workers (12.2\%) and administrative staff (14.2\%).

Analysis using multiple regression indicated that GHQ-28 score, level of emotional exhaustion and score on the JDS were the most reliable predictors of work stress. Mean score on the JDS was 9.3, suggesting participants were fairly satisfied with their work in a general sense. GHQ-28 scores indicated respondents to be most likely to suffer symptoms of anxiety and worry.

Although mean scores for this sample on the measures for stress and burn-out were not high. we were alarmed to find at least $10 \%$ had taken time off sick during the past year as a result of work pressures (self-reported). Moreover, more than one in three of the child and adolescent mental health team staff stated that their level of stress affected their ability to work with disordered families.

We agree that much can be done by employing organisations to reduce the impact of work stress and burn-out: we would advocate a greater development of supportive supervisory mechanisms as a means of alleviating work-based stress.

\section{References}

COOPER, C., COOPER, R. D. \& EAKER, L. H. (1988) Living with Stress. London: Penguin.

GolDBERG, D. \& WILIAMS, P. (1988). A User's guide to the General Health Questionnaire. Windsor: NFER Nelson.

HACKMAN, J. R. \& OLDHAM, G. R. (1975) Development of the Job Diagnostic Survey. Joumal of Applied Psychology. 60, 159-170.

MASLACH, C. \& JACKSON, S. E. (1986) Maslach Burnout Inventory Manual (2nd edn). Palo Alto, CA: Consulting Psychologists Press.

PAMEla CASE, Registered Mental Nurse, Wirral and West Cheshire Community NHS Trust, Clatterbridge Hospital, Bebington, Wirral CH63 4JY; and STEPHEN LITTLEWOOD, Consultant Child and Adolescent Psychiatrist, Family and Child Therapy Service, Clinic Centre, Stanney Lane, Ellesmere Port, Cheshire CH65 9AE

\section{Political correctness}

Sir: A light-hearted discussion with a colleague a few weeks ago on the new politically correct 
terminology creeping into psychiatry led me to survey the opinions of professional colleagues and patients as to their preferences.

They were offered the following options although also encouraged to make their own suggestions and comments.

(a) Patient, client, customer, sufferer or user.

(b) Mental hospital, psychiatric hospital, mental health unit or resource centre.

(c) Mental illness, psychiatric illness or ongoing illness.

(d) Nurse, keyworker or care worker.

(e) Drugs, medicines or medication.

Fifty-five out-patients responded with $87 \%$ $(n=48)$ preferring to be called patients, $54 \%$ $(n=30)$ wished to attend a mental health visit and $47 \%(n=26)$ preferred to be described as having a mental illness. Fifty per cent $(n=28)$ wished to be cared for by a nurse and $62 \%(n=34)$ took medication.

Alternative suggestions to currently used terms were stress-related illness and nervous complaint. One patient commented that changing terms added confusion and disguised the real purpose of the service.

Only $15(38 \%)$ of 39 general practitioners responded but of these $14(93 \%)$ preferred patient and one response to the term 'client' was "YUK!" Eleven (73\%) preferred the term mental health unit, but there was fairly even split between mental illness and psychiatric illness and also nurse and keyworker. Thirteen (86\%) preferred the term medication.

One particular comment was the hope that we could get rid of some of the ridiculous politically correct terms that have infected mental health services in recent years.

In-patient staff also responded. Of the 14, eight (57\%) preferred the term patient, $13(92 \%)$ mental health unit and $11(79 \%)$ psychiatric illness. There was an even split between nurse and keyworker and $13(92 \%)$ preferred the term medication.

In the current climate of destigmatisation it is important that in introducing new terminology we do not cause greater problems in terms of confusion and discomfort for patients and professionals alike.

Christine M. TYRIE, Consultant Psychiatrist, Penrith and Eden Community Hospitals, Bridge Lane, Penrith, Cumbria CA11 8HX

\section{What is a lecturer?}

In clinical medical disciplines lecturers are like senior lecturers and professors and face a threeway split. Traditionally they have contracts which give approximately half of their time to the National Health Service. It is logical to assume that their research and teaching output would be at most half that of non-clinical lecturers. Unfortunately, under the pressure of the Research Assessment Exercise (RAE) many universities regard lecturers as full-time staff who should be as productive as non-clinical lecturers. The problem is compounded because lecturers are also in training posts equivalent to the 'Calman' specialist registrar (SpR). These have strict educational requirements and timetables regulated by the appropriate Higher Specialist Training Committee.

What possible ways are there out of these

difficulties? There are at least five options:

(a) Lecturer posts should only be offered to those who already have an established research training, perhaps through a research fellowship. They would come to a lecturer post with the realistic prospect of competitive research awards and potential early publications.

(b) Lecturer posts should be regarded as development posts for those who are intent on an academic career. They should only be filled after a full SpR training and with only two sessions per week clinical commitments. This happens now in some medical specialities.

(c) Posts are created which combine academic responsibility, especially to conduct clinical research, with clinical work but are only filled by those with approved research plans as currently occur with Research Council funded posts.

(d) The 'three-way' split of time between teaching, clinical work and research is accepted as unworkable and incompatible with higher training. It is reduced to a twoway split by designation of some posts as teaching/clinical and others as research/ clinical.

(e) Some lecturer posts are re-designated as honorary 'academic' SpR posts, and thus removed from the university payroll and the RAE.

Each of these options may be appropriate in certain circumstances. Each has its own balance of benefits and problems. These may be resolved if those in the Royal Colleges who are responsible for maintaining training standards and those in the universities who are responsible for teaching and research work together to develop, consider and implement workable solutions. Clinical lecturer posts should not be allowed to atrophy by neglect.

JOHN WATTIS, Medical Director, LAWRENCE WHALLEY and PETER TYRER, Leeds Community and Mental Health Services, The Mansion, Meanwood Park Hospital, Tongue Lane, Leeds LS6 4QB 